Supplement of Geosci. Model Dev., 13, 2259-2276, 2020

https://doi.org/10.5194/gmd-13-2259-2020-supplement

(C) Author(s) 2020. This work is distributed under

the Creative Commons Attribution 4.0 License.

(c) (1)

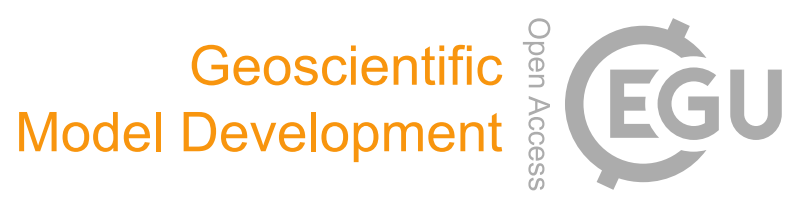

Supplement of

\title{
Evaluating integrated surface/subsurface permafrost thermal hydrology models in ATS (v0.88) against observations from a polygonal tundra site
}

\author{
Ahmad Jan et al. \\ Correspondence to: Scott L. Painter (paintersl@ornl.gov)
}

The copyright of individual parts of the supplement might differ from the CC BY 4.0 License. 
Table S1. Quantitative measures of model performance to observed soil temperatures for the period 2012-2014. Notation: NSE (Nash-Sutcliffe model efficiency coefficient), RMSE (Root Mean Squared Error), and $R_{2}$ (Coefficient of determination). Warm (or cold) bias in the model is represented by positive (or negative) bias

\begin{tabular}{|l|l|l|l|l|l|}
\hline \multicolumn{2}{|l|}{ Depth [m] } & Location & \multicolumn{5}{l|}{ Efficiency metrics } \\
\hline \multicolumn{2}{|l|}{} & NSE & RMSE & R2 & Bias \\
\hline 0.05 & Center & 0.94 & 1.88 & 0.94 & -0.48 \\
\hline 0.5 & Center & 0.94 & 1.38 & 0.95 & -0.06 \\
\hline 1.5 & Center & 0.95 & 0.88 & 0.95 & 0.27 \\
\hline & & & & & \\
\cline { 3 - 6 } & & & & & \\
\hline 0.05 & Rim & 0.94 & 2.03 & 0.95 & -0.44 \\
\hline 0.5 & Rim & 0.88 & 1.86 & 0.93 & -0.36 \\
\hline 1.5 & Rim & 0.96 & 0.88 & 0.94 & -0.12 \\
\hline & & & & & \\
\cline { 3 - 6 } & & & & & \\
\hline 0.05 & Trough & 0.94 & 1.79 & 0.95 & -0.38 \\
\hline 0.5 & Trough & 0.95 & 1.25 & 0.95 & -0.08 \\
\hline 1.5 & Trough & 0.96 & 0.79 & 0.95 & 0.15 \\
\hline
\end{tabular}
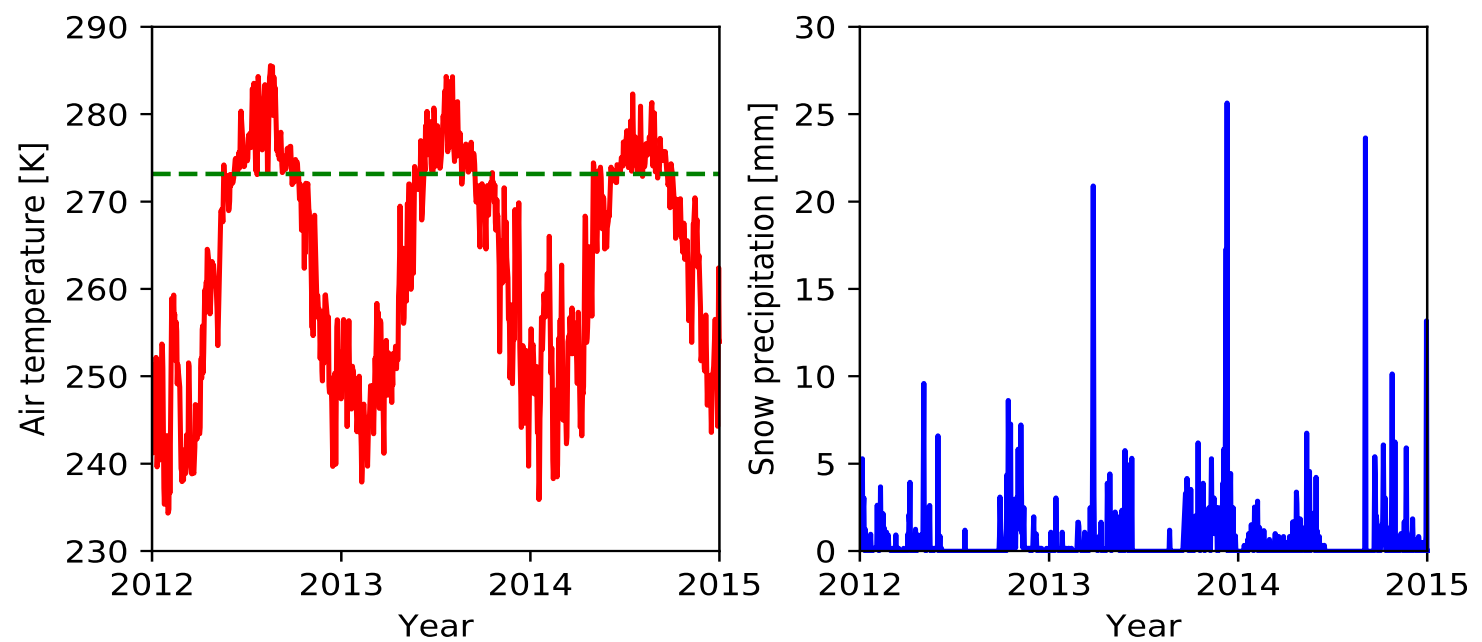

Figure S1: Daily averaged air temperature and precipitation at the study area for years 2012-2015. 

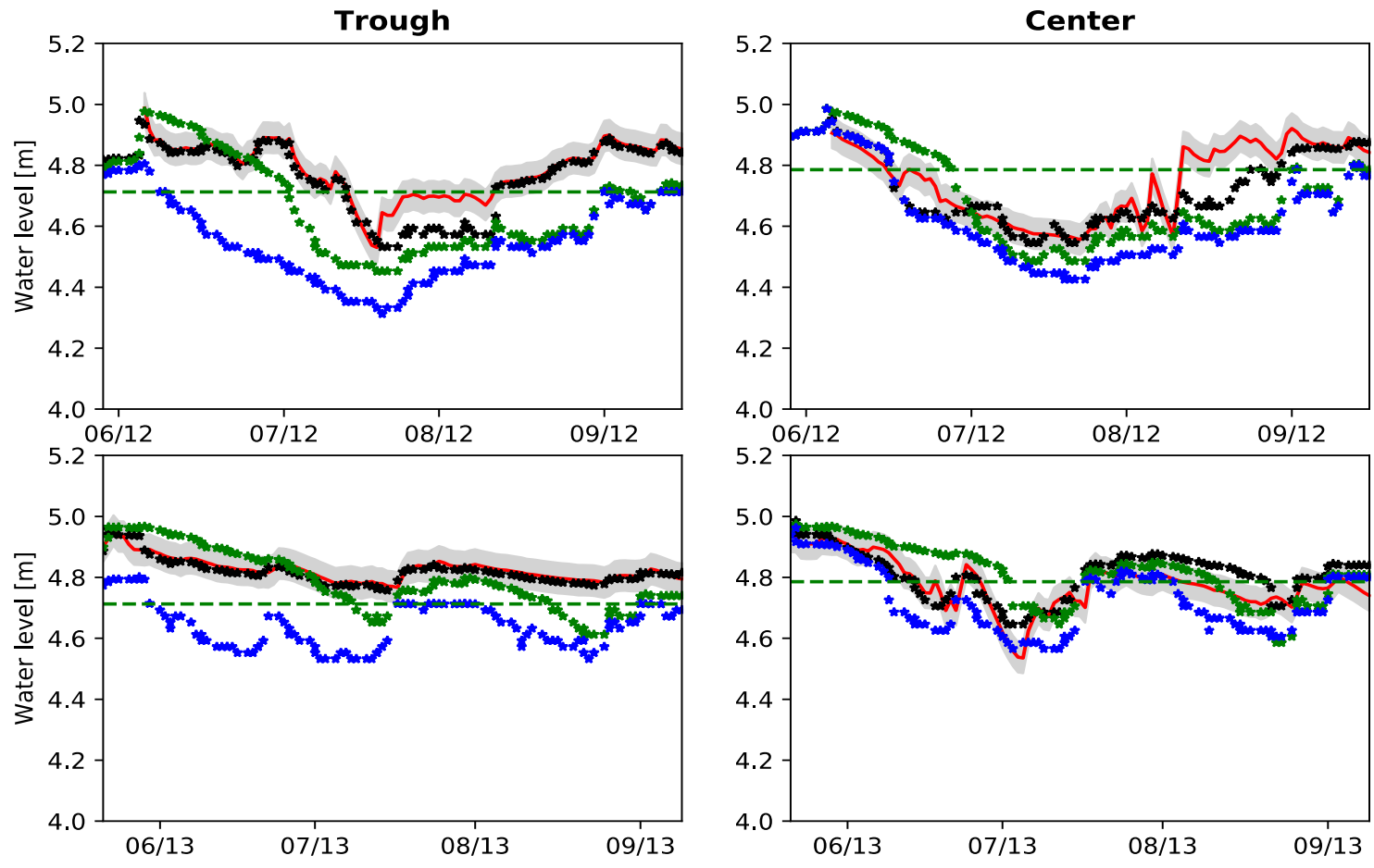

- Observed

* Basecase

Closed boundary * Seepage face

Figure S2: Shown in the observed and simulated water tables from different boundary conditions. Results demonstrate that run-off is important during snowmelt run-on to polygon is mportant during dry summer periods. 

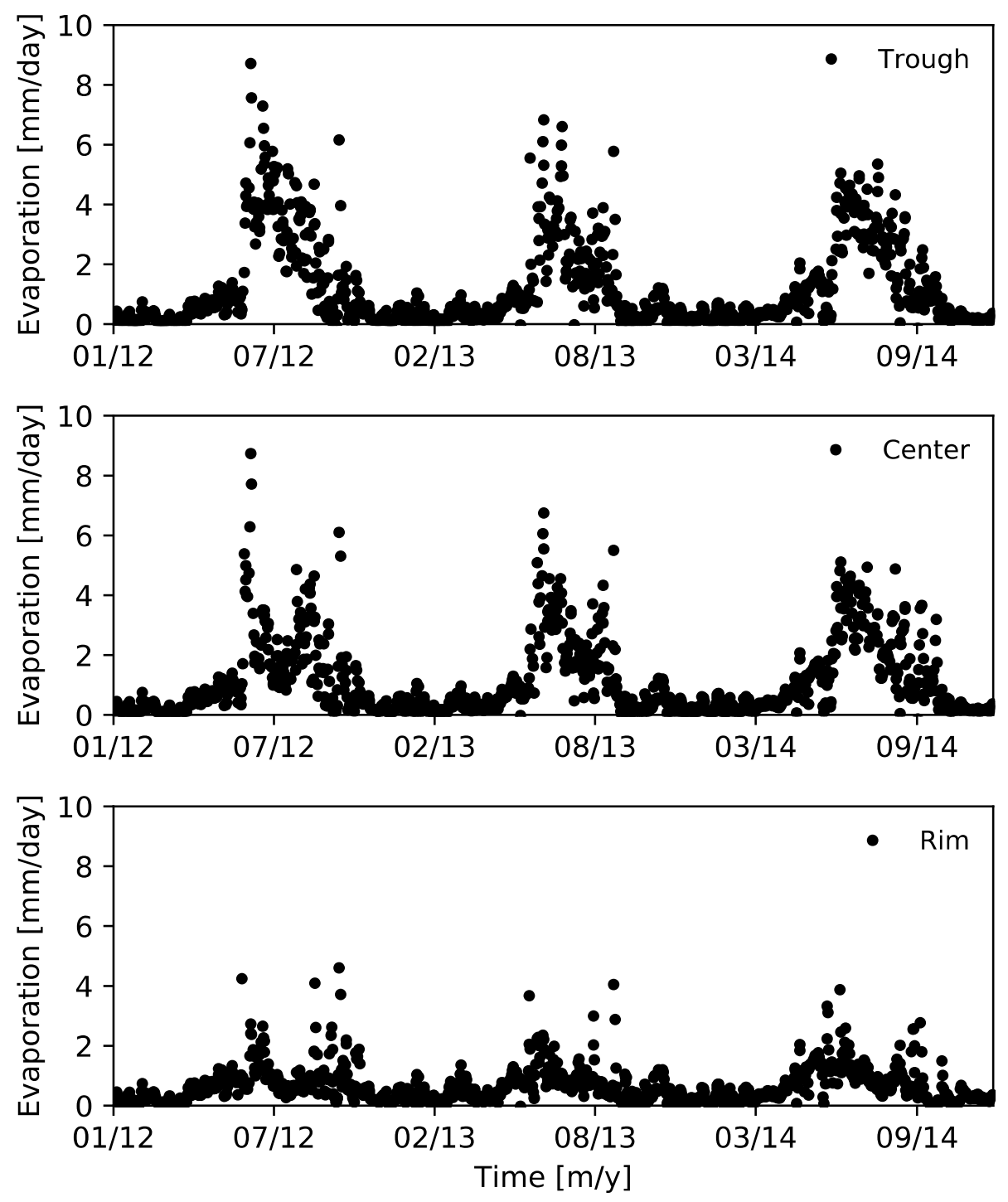

Figure S3: Simulated evaporation versus time for trough, center, and rim microtopographic positions. 